\title{
RISIKO MENDERITA KANKER DAN NON KANKER PADA PEKERJA TERPAPAR BENZENA DI HOME INDUSTRY SEPATU KELURAHAN TAMBAK OSO WILANGUN SURABAYA
}

\author{
Heru Fahrudhi \\ PT.Roda Konstruksi Utama \\ Jl. Raya Legok 3 RT 003/02, Legok, Tangerang 15820 \\ Email: heru.kaspa@gmail.com
}

\begin{abstract}
Home footwear industry in operations using benzena-based glue, therefore, workers at home industry is at risk for exposure to benzena vapor. Toxic effects of exposure to benzena can form cancer (leukemia) and non-cancerous (aplastic anemia). Work to make the shoes is a job that has a risk of harm. The general objective of this study was to assess the extent of the risk of cancer and non cancer caused by exposure to benzena in shoe craftsmen working in the village Tambak Oso Wilangun Surabaya. This study is an observational study conducted in the shoes industry craftsmen in the village Tambak Oso Wilangon Surabaya. The formula for calculating the RQ (Risk Quotient) and ECR (Excess Cancer Risk) using the formula Louver \& Louver. The study design using the design of the risk analysis paradigm of risk assessment. Benzena levels measured in the workplace air ranged from $0.04 \mathrm{mg} / \mathrm{m}^{3}$ to $7.44 \mathrm{mg} / \mathrm{m}^{3}$. The calculation result obtained $R Q R Q \leq 1$ of 8 people (40\%) and $R Q>1$ as many as 13 people (60\%) and the calculation of the ECR obtained all workers with ECR value $>10^{-5}$ as many as 20 people (100\%). Conclusion of research is there risk to the workers' non-carcinogenic health effects and all workers have exposure to carcinogenic health effects.
\end{abstract}

Keywords: risk, glue, benzena, $R Q, E C R$

\begin{abstract}
ABSTRAK
Home industry sepatu dalam operasionalnya menggunakan yang berbasis benzena, oleh karena itu pekerja di home industry tersebut berisiko untuk terpapar uap benzena. Efek toksik dari paparan benzena dapat berbentuk kanker (leukemia) dan non kanker (anemia aplastik). Pekerjaan membuat sepatu merupakan pekerjaan yang memiliki risiko bahaya. Tujuan umum dari penelitian ini adalah untuk mengkaji besarnya risiko terjadinya kanker maupun non kanker akibat paparan benzena pada pekerja pengrajin sepatu di Kelurahan tambak Oso Wilangun Surabaya. Penelitian ini merupakan penelitian observasional yang dilakukan di industri pengrajin sepatu di kelurahan Tambak Oso Wilangun Surabaya. Rumus untuk menghitung besaranya RQ dan ECR menggunakan formula Louver and Louver. Rancangan penelitian menggunakan desain paradigma risk analysis yakni penilaian risiko. Kadar benzena yang diukur di udara tempat kerja berkisar antara 0,04 mg/ $\mathrm{m}^{3}$ hingga 7,44 mg/m $\mathrm{m}^{3}$. Hasil perhitungan RQ didapatkan RQ $\leq 1$ sebanyak 8 orang (40\%) dan RQ $>1$ sebanyak 13 orang $(60 \%)$ dan perhitungan ECR didapatkan seluruh pekerja dengan nilai ECR $>10^{-5}$ sebanyak 20 orang (100\%). Kesimpulan penelitian adalah terdapat pekerja memiliki risiko terhadap efek kesehatan non karsinogenik dan seluruh pekerja memiliki risiko terhadap efek kesehatan karsinogenik.
\end{abstract}

Kata kunci: risiko, lem, benzena, RQ, ECR

\section{PENDAHULUAN}

Perkembangan industri di Indonesia yang mengalami pertumbuhan dengan pesat mendorong adanya tuntutan akan berbagai kebutuhan macam produk. Untuk memenuhi kebutuhan tersebut banyak didirikan industri baik dengan skala besar maupun kecil seperti Usaha kecil Menengah (UKM). Home industry atau UKM ini didirikan agar masyarakat mampu mengembangkan usaha sehingga mampu menciptakan lapangan kerja dan mengurangi tingkat pengangguran di Indonesia.
Usaha Kecil Menengah (UKM) memiliki peran yang sangat penting dalam meningkatkan perekonomian nasional. UKM mampu menciptakan lapangan kerja, memproduksi barang dan layanan yang sesuai dengan kebutuhan masyarakat. UKM membuktikan dirinya sebagai kelompok tangguh dan fleksibel, serta masih bertahan dan menyumbang pertumbuhan ekonomi nasional secara signifikan (ILO, 2008).

Salah satu UKM yang ada di Indonesia adalah industri informal pengrajin sepatu. Di awal tahun 1990-an, industri sepatu menjadi penyumbang 
utama untuk Produk Nasional Bruto Indonesia sebagai pendapatan nasional ketiga terbesar setelah industri kayu dan tekstil. Sekitar 40 persen dari ekspor sepatu Indonesia dikirim ke pasar Amerika Serikat, sedangkan 33 persen dikirim ke Eropa dan sisanya diekspor ke negara-negara Afrika, Timur Tengah dan Amerika Selatan. Di masa puncaknya pada tahun 1996, Indonesia mengekspor 250 juta pasang sepatu senilai hampir US\$2.19 milyar. Sejak saat itu, volume ekspor industri sepatu mengalami penurunan hingga pada tahun 2002 ekspor industri sepatu hanya sebesar US\$1.4 milyar. Walaupun ada penurunan ekspor akibat krisis ekonomi, namun produksi sepatu tetap merupakan salah satu industri yang utama di Indonesia (ILO, 2004). Pada tahun 2013 nilai ekspor sepatu Indonesia mencapai US\$ 3,86 milyar, dengan nilai ekspor tersebut Indonesia mampu memenuhi sekitar tiga persen kebutuhan dunia produk sepatu (Kemenperin, 2017).

Usaha para pengrajin sepatu untuk menjaga kualitas dan eksistensi dari produknya seringkali tidak diimbangi dengan perlindungan terhadap risiko pekerjaan yang berhubungan dengan peralatan dan bahan berbahaya. Penggunaan bahan berbahaya atau bahan kimia berbahaya pada pengrajin sepatu seperti menggunakan lem sebagai bahan untuk proses pembuatan sepatu. Prosesnya terdiri dari beberapa tahapan pekerjaan, dimulai dari pembuatan desain/pola pembuatan sepatu, mempersiapkan bagian atas sepatu (membuat pola, memotong pola, menggaris, mendekorasi, menjahit dan sol bagian dalam), mempersiapkan bagian bawah sepatu (sol bagian luar, mengelem, melapisi), memasang bagian atas sepatu dan bawah sepatu (mengelem, menjahit, memaku), penyelesaian/finishing (membersihkan, menghaluskan), mengepak untuk selanjutnya dikirim ke konsumen/pasar dalam proses produksinya menggunakan beragam peralatan (Maryiantari, 2016).

Pekerjaan membuat sepatu merupakan pekerjaan yang memiliki risiko bahaya. Jam kerja yang panjang, namun tidak didukung oleh tempat kerja yang aman dan nyaman, posisi tubuh yang kurang nyaman, dan penggunaan peralatan yang berbahaya. Peralatan yang dipakai dalam proses produksi seperti mesin pemanas listrik/ api (oven), paku dan martil. Bahan baku terbuat dari kain, kulit sintetis atau bahan plastik. Untuk proses pengeleman memakai dua jenis lem yaitu lem kuning Merk Pro ARdico, lem LK dan lem putih merk PU-Weber, DS-Bond DNS 818. Lem kuning digunakan untuk menyambung bukaan sehingga biasanya digunakan di bagian permukaan dan finishing, sedangkan lem putih umumnya digunakan untuk tempelan sol karena daya rekatnya yang jauh lebih kuat. Pada situasi normal (hari biasa) dalam waktu satu bulan bisa menghabiskan 30-40 kg lem kuning dan lem putih kurang lebih $30 \mathrm{~kg}$. Pemakaian lem dituangkan dalam wadah kecil seperti botol bekas minuman, gelas dengan posisi terbuka atau langsung dari wadah lem ukuran $3 \mathrm{~kg}$ (Maryiantari, 2016). Berdasarkan penelitian yang dilakukan oleh Hendra menyatakan bahwa terdapat pelarut organik dalam lem berupa pelarut benzena sekitar 1-2\%.

Dari berbagai peralatan dan bahan yang digunakan, bahan kimia dalam proses pembuatan sepatu merupakan salah satu risiko bahaya yang tinggi. Penggunaan bahan kimia dapat mengganggu kesehatan para pengrajin sepatu salah satunya penggunaan lem. Karena dalam proses tersebut terdapat pajanan uap pelarut organik yang terkandung dalam lem dan sangat mungkin menimbulkan dampak pada kesehatan bila terhirup terus menerus dalam jangka waktu lama (Lu, 2006). Masuknya uap pelarut organik ke dalam tubuh dapat menyebabkan beragam reaksi, seperti iritasi ringan, kecanduan, gangguan ginjal, reaksi odema paru sampai dengan gangguan sistem syaraf pusat (National Occupatioanl Health and Safety Commision, 1990).

Pelarut organik berbahaya yang banyak digunakan pada beragam industri sepatu di Indonesia adalah benzena, taluena, dan xilena. Benzena apabila masuk ke dalam tubuh dalam bentuk gas, padat, maupun cairan. Menyebutkan bahwa rute pajanan utama terjadi melalui inhalasi, walaupun pada pajanan secara dermal kontak dengan kulit dan oral mungkin dapat terjadi (ATSDR, 2007). Benzena yang masuk ke dalam tubuh akan mengalami metabolisme yang utama menjadi benzena epoksida. Di dalam hati, benzena epoksida merupakan senyawa yang tidak stabil dan akan segera mengalami perubahan membentuk fenol yang akan dikeluarkan melalui urin. Oleh karena itu kadar fenol digunakan sebagai indicator biologic atas paparan benzena pada tenaga kerja (Sugiharto, 2009; Krogholm, 2010).

Penggunaan benzena, ditemukan juga dampak kesehatan akibat pemajanan dengan bahan kimia ini. Benzena apabila terinhalasi, dapat menyebabkan anemia aplastik dan leukemia. Hasil penelitian yang dilakukan di Eropa, Amerika, dan Meksiko telah menunjukkan adanya hubungan yang nyata antara peningkatan kadar benzena di udara dengan peningkatan kasus kanker dan leukimia penduduk 
setempat. Dalam penelitian lainnya di Amerika Serikat, telah terbukti bahwa menghirup benzena walaupun dalam ambang batas dapat menyebabkan abnormalitas kromosom pada sel sperma.

Standar Nasional Indonesia tahun 2005 yang mengacu pada Permenaker No. 13 tahun 2011 memuat tentang Nilai Ambang Batas (NAB) rata-rata tertimbang waktu (time weighted avarage) zat kimia di udara tempat kerja, dengan jumlah jam kerja 8 jam per hari atau 40 jam per minggu, menyatakan bahwa benzena yang dimasukkan dalam kelompok A2 (zat kimia yang diperkirakan karsinogen untuk manusia) memiliki NAB adalah sebesar $10 \mathrm{ppm}$ atau $32 \mathrm{mg} / \mathrm{m}^{3}$ benzena di udara (SNI 2005).

Kasus-kasus kesehatan yang berhubungan dengan pajanan benzena telah banyak ditemukan di beberapa negara. Kasus pajanan benzena pertama kali ditemukan di Maryland (USA) pada 1909 dimana 4 orang gadis berusia 14 tahun menderita kelumpuhan dan pendarahan selaput otak. Sementara itu efek kronik keracunan benzena pertama kali ditemukan oleh Lesse di Inggris pada tahun 1920 pada 2 orang pekerja pabrik balon. Lesse menemukan pencemaran udara lingkungan kerja dengan konsentrasi benzena sebesar 210 ppm-800 ppm. Benzena juga dapat mengakibatkan abortus (Susilowati, 2011).

Kejadian gangguan kesehatan akibat pajanan benzena pada pekerja bengkel sepatu dilaporkan terjadi di China, yang merupakan produsen sepatu terbesar di dunia. Sebuah studi kohort restrospektif terhadap 75.000 pekerja terpapar benzena pada tahun 1987 hingga 1991 di 12 kota di China menemukan bahwa sebanyak 43 kelompok pekerja terpapar benzena. Studi ini mengemukakan bahwa pekerja yang terpapar benzena lebih berisiko terkena kematian akibat leukimia dengan risiko relatif sebesar 2,3 dibanding dengan pekerja yang tidak terpapar benzena (Chen dan Chan, 1999).

Beberapa kasus akibat penggunaan benzena pada industri sepatu adalah pada tahun 1946-1956 di Amerika Serikat terdapat 107 kasus akibat konsentrasi pemajanan benzena yang melebihi 400 ppm. Dari kasus tersebut ditemukan hemeophaty dan thrombocytopenia (George \& Fleorance, 1994). Pada 1945-1955 terdapat 125 kasus penurunan trombosit dan ketidaknormalan fungsi hati dikarenakan pemajanan benzena yang melebihi 400 ppm pada industri sepatu. Sedangkan pada tahun 1948, API (American Petroleum Institute) mempublikasikan bahwa benzena dipastikan dapat menyebabkan leukimia dan tidak ada toleransi sekecil apapun (zero ppm level) terhadap emisi benzena. Pada tahun 1971 di Amerika terdapat 51 kasus leucopenia, pancytopenia, eoainophilia, thrombocytopenia, basophilia, pembesaran platelet dan anemia akibat pemajana benzena dengan konsentrasi antara 30-210 ppm (George \& Fleorance, 1994).

\section{METODE}

Penelitian ini merupakan penelitian observasional yang dilakukan di industri pengrajin sepatu kelurahan Tambak Oso Wilangun Surabaya. Sedangkan dari segi waktu, jenis pendekatan yang digunakan dalam penelitian ini adalah crosssectional, rancangan penelitian menggunakan desain paradigma risk analysis dengan mengambil salah satu komponennya, yakni penilaian risiko/ risk assessment (NRC, 1983). Penilaian risiko digunakan untuk menghitung perkiraan tingkat risiko kesehatan dan menentukan pengendalian berupa waktu pajanan (Dt) aman. Langkah yang dilakukan dalam penilaian risiko adalah: identifikasi bahaya, analisis pemajanan, analisis dosis respons dan karakteristik risiko. Penelitian ini dilakukan pada 8 lokasi kerja dengan subyek penelitian 20 orang responden. Pengukuran konsentrasi benzena di lingkungan kerja, dilakukan dengan menggunakan metode pengukuran NIOSH 1501 dengan pipa pengadsorbsi karbon aktif (choarcoal) yaitu dengan menggunakan teknik Gas Chromatography (GC) oleh petugas dari UPTK3 Surabaya.

\section{HASIL}

Benzena di lingkungan pekerja pengrajin sepatu merupakan hal yang mutlak ditemukan untuk mengetahui tingkat risiko kelompok terpajan. Penelitian ini mengukur 8 lokasi kerja untuk mengetahui gambaran konsentrasi benzena.

Pada tabel 1 diketahui konsentrasi benzena sebanyak 6 titik (75\%) masih berada di bawah nilai ambang batas yang ditentukan sebanyak $0,5 \mathrm{ppm}$ atau $1,6 \mathrm{mg} / \mathrm{m}^{3}$. Rerata konsentrasi benzena sebesar $1,6313 \mathrm{mg} / \mathrm{m}^{3}$. Tingkat konsentrasi paling rendah sebesar $0,04 \mathrm{mg} / \mathrm{m}^{3}$ dan tingkat konsentrasi paling tinggi sebesar $7,44 \mathrm{mg} / \mathrm{m}^{3}$.

Pada pola aktivitas yang akan dibahas meliputi pajanan, frekuensi dan durasi pajanan. Karena pekerja merupakan pemilik dari usaha home industry sepatu maka jam kerja dari setiap lokasi kerja tidak sama. Selain jam kerja variabel lain yang harus diperhatikan adalah jumlah hari kerja dan lama 
bekerja pekerja di home industry sepatu Tambak Oso Wilangun.

Tabel 2 menggambarkan distribusi frekuensi waktu pajanan, frekuensi pajanan, dan durasi pajanan. Waktu pajanan (tE) dikategorikan menjadi dua yaitu $\leq 8 \mathrm{jam} / \mathrm{hari}$ dan $>8 \mathrm{jam} / \mathrm{hari}$. Hasil penelitian didapatkan sebanyak 1 pekerja (5\%) memiliki waktu pajanan $\leq 8 \mathrm{jam} / \mathrm{hari}$ dan sebanyak 19 pekerja (95\%) memiliki waktu pajanan $>8$ jam/hari. Rata-rata waktu pajanan 10,55 jam/ hari ini menunjukkan bahwa setiap lokasi kerja memiliki waktu pajanan yang berbeda satu sama lain. Frekuensi pajanan (fE) dikategorikan menjadi dua yaitu $\leq 265$ hari dan $>265$ hari. Hasil penelitian didapatkan seluruh pekerja memiliki frekuensi pajanan $>265$ hari. Rata-rata pekerja dalam setahun bekerja selama 346,75 hari. Durasi pajanan (Dt) dikategorikan menjadi dua yaitu $\leq 25$ tahun dan $>$ 25 tahun. Hasil penelitian menunjukkan hasil yang berimbang diantara keduanya, masing-masing 10 pekerja (50\%). Rata-rata durasi pajanan 24,93 tahun.

Tabel 1. Distribusi Konsentrasi Benzena di Lingkungan Kerja Pengrajin Sepatu di Kelurahan Tambak Oso Wilangun Surabaya 2016

\begin{tabular}{|c|c|c|}
\hline $\begin{array}{c}\text { Konsentrasi Benzena } \\
\left(\mathrm{NAB}=1,6 \mathrm{mg} / \mathrm{m}^{3}\right)\end{array}$ & $\mathbf{n}$ & $\begin{array}{c}\text { Persentase } \\
(\%)\end{array}$ \\
\hline$\leq 1.6 \mathrm{mg} / \mathrm{m}^{3}$ & 6 & 75 \\
\hline$>1.6 \mathrm{mg} / \mathrm{m}^{3}$ & 2 & 25 \\
\hline Total & 8 & 100 \\
\hline Mean & \multicolumn{2}{|c|}{1.3475} \\
\hline Median & \multicolumn{2}{|c|}{0.6350} \\
\hline Std. Deviation & \multicolumn{2}{|c|}{2.54762} \\
\hline Min-Max & \multicolumn{2}{|c|}{$0.04-7.44$} \\
\hline
\end{tabular}

Berdasarkan hasil wawancara diketahui pekerja merupakan pekerja yang sudah lama menekuni pekerjaan dan sudah lama bekerja sebelumnya, oleh karena itu perlu diperhatikan masa kerja karena hal ini dapat memberikan gambaran bahwa mereka selalu berada pada lingkungan yang memungkinkan terpajan benzena.

Hasil penelitian diketahui salah seorang responden dengan nomor urut 1 mempunyai berat badan sebesar $51.4 \mathrm{Kg}\left(\mathrm{W}_{\mathrm{b}}\right.$, setiap hari bekerja 9 $\mathrm{jam} /$ hari (tE), jumlah hari kerja selama satu tahun 313 hari (fE), dan telah bekerja selama 34 tahun (Dt). Dengan laju inhalasi (R) sebesar $0,6 \mathrm{~m}^{3} / \mathrm{jam}$ dan $t_{\text {avg }}$ untuk zat karsinogenik adalah 10950 hari. Dengan hasil pengukuran udara benzena yang memiliki konsentrasi benzena (C) $0,04 \mathrm{mg} / \mathrm{m}^{3}$, sehingga besarnya intake (asupan) nonkarsinogenik adalah :

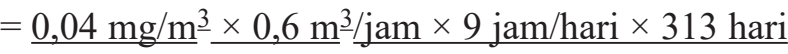
$\times 34$ tahun

$51.4 \mathrm{Kg} \times 10950$ hari

$=0,004084 \mathrm{mg} / \mathrm{kg} \cdot$ hari

Jadi intake (asupan) benzena per hari untuk pekerja pertama tersebut adalah $0,004084 \mathrm{mg} /$ kg.hari. Sedangkan untuk perhitungan intake (asupan) karsinogenik menggunakan rumus dan nilai variabel yang sama namun dengan menggunakan $t_{\text {avg }}$ untuk zat karsinogenik adalah 25550 hari. Berikut perhitungan Intake (asupan) karsinogenik perhari pekerja pertama:

$=\underline{0,04 \mathrm{mg} / \mathrm{m}^{3}} \underline{\underline{3}} \underline{0,6 \mathrm{~m}}=\frac{3}{\mathrm{jam} \times 9} \mathrm{jam} / \mathrm{hari} \times 313$ hari $\underline{\mathrm{x}} 34$ tahun

$51.4 \mathrm{Kg} \times 25550$ hari

$=0,0018 \mathrm{mg} / \mathrm{kg} \cdot$ hari

Tabel 2. Distribusi Deskriptif Frekuensi Pola Aktivitas Pekerja Pengrajin Sepatu di Kelurahan Tambak Oso Wilangun Surabaya 2016

\begin{tabular}{|c|c|c|c|c|c|c|c|c|c|}
\hline \multirow[t]{2}{*}{ Ket. } & \multirow{2}{*}{ (tE) } & \multicolumn{2}{|c|}{ Jml } & \multirow{2}{*}{ (fE) } & \multicolumn{2}{|c|}{ Jml } & \multirow{2}{*}{ (Dt) } & \multicolumn{2}{|c|}{ Jml } \\
\hline & & $\mathbf{n}$ & $\%$ & & $\mathbf{n}$ & $\%$ & & $\mathbf{n}$ & $\%$ \\
\hline \multirow[t]{3}{*}{$\mathrm{w}$} & $\leq 8 \mathrm{jam}$ & 1 & 5 & $\leq 265$ hari & - & - & $\leq 25$ th & 10 & 50 \\
\hline & $>8 \mathrm{jam}$ & 19 & 95 & $>265$ hari & 20 & 100 & $>25$ th & 10 & 50 \\
\hline & & 20 & 100 & & 20 & 100 & & 20 & 100 \\
\hline \multicolumn{2}{|c|}{ Rata-rata } & \multicolumn{2}{|c|}{10.55} & & \multicolumn{2}{|c|}{346.75} & & \multicolumn{2}{|c|}{24.93} \\
\hline \multicolumn{2}{|l|}{ Std. dev } & \multicolumn{2}{|c|}{3.086} & & \multicolumn{2}{|c|}{30.680} & & \multicolumn{2}{|c|}{10.957} \\
\hline Med & Jam/hari & \multicolumn{2}{|c|}{9.50} & hari/thn & \multicolumn{2}{|c|}{365} & tahun & \multicolumn{2}{|c|}{24.50} \\
\hline Min & & \multicolumn{2}{|c|}{6} & & \multicolumn{2}{|c|}{260} & & \multicolumn{2}{|c|}{3} \\
\hline Max & & \multicolumn{2}{|c|}{17} & & \multicolumn{2}{|c|}{365} & & \multicolumn{2}{|c|}{43} \\
\hline
\end{tabular}


Jadi intake (asupan) benzena perhari untuk pekerja pertama tersebut adalah $0,0018 \mathrm{mg} / \mathrm{kg}$.hari.

Karakteristik risiko untuk efek nonkanker dapat diketahui dengan membagi nilai Intake Nonkanker dengan nilai $R f D$ atau $R f C$ dengan rumus sebagai berikut:

$$
R Q=\frac{I_{n k}}{R f D \text { atau } R f C}
$$

Setelah atau diperoleh nilai RQ maka digunakan asumsi Jika nilai $R Q \leq 1$ menunjukkan indikasi tidak adanya kemungkinan terjadinya risiko efek kesehatan nonkarsinogenik, namun perlu dipertahankan agar nilai numerik $R Q$ tidak melebihi 1 . Sedangkan $R Q$ $>1$ menunjukkan indikasi adanya kemungkinan terjadinya risiko efek kesehatan nonkarsinogenik dan perlu adanya upaya pengendalian (Rahman dkk., 2007).

Berdasarkan tabel diatas diketahui bawah hasil perhitungan RQ saat ini adalah RQ $\leq 1$ sebanyak 8 orang $(40 \%)$ dan RQ $>1$ sebanyak 13 orang $(60 \%)$, untuk pajanan 5 tahun RQ $\leq 1$ sebanyak 7 orang $(35 \%)$ dan RQ $>1$ sebanyak 13 orang (65\%). Untuk pajanan 10 tahun dan 15 tahun menunjukkan hasil yang sama yaitu $R Q \leq 1$ sebanyak 6 orang $(30 \%)$ dan RQ $>1$ sebanyak 14 orang $(70 \%)$. Untuk pajanan 20 tahun dan 25 tahun menunjukkan hasil yang sama yaitu RQ $\leq 1$ sebanyak 5 orang (25\%) dan RQ $>1$ sebanyak 15 orang $(75 \%)$. Sedangkan untuk pajanan 30 tahun yaitu RQ $\leq 1$ sebanyak 4 orang $(20 \%)$ dan RQ $>1$ sebanyak 16 orang (80\%). Semakin lama pajanan benzena terhadap pekerja maka semakin berisiko terhadap efek kesehatan nonkarsinogenik terbukti pada pajanan tahun ke 10 hingga 15 dan 20 hingga 25 tahun dan pajanan 30 tahun menunjukkan peningkatan jumlah pekerja yang berisiko terhadap efek kesehatan nonkarsinogenik.

Karakteristik risiko untuk efek kanker dapat diketahui dengan mengalikan nilai Intake kanker dengan nilai $C S F$ dengan rumus sebagai berikut:

\section{$\mathbf{E C R}=$ Intake Karsinogenik $\left(\mathrm{I}_{\mathrm{k}}\right) \times \mathrm{CSF}$}

Jika ECR $\leq 10^{-5}$, maka konsentrasi pajanan benzena terhadap pekerja belum berisiko menimbulkan efek kesehatan karsinogenik Jika ECR $>10^{-5}$, maka konsentrasi pajanan benzena terhadap pekerja dapat menimbulkan efek kesehatan karsinogenik.

Dari hasil perhitungan ECR diketahui bahwa nilai ECR untuk pajanan saat ini, 5 tahun hingga 30 seluruh pekerja dengan nilai ECR $>10^{-5}$ sebanyak 20 orang $(100 \%)$ dalam kondisi berisiko terhadap efek kesehatan kanker.

Tabel 3. Persentase RQ saat ini, 5 th, 10 th, 15 th, 20 th, 25 th, dan 30 th Pekerja Pengrajin Sepatu di Kelurahan Tambak Oso Wilangun Surabaya 2016

\begin{tabular}{|c|c|c|c|c|}
\hline \multirow{2}{*}{ Pajanan } & \multirow{2}{*}{ (RQ) } & \multicolumn{2}{|c|}{ Jumlah } & \multirow{2}{*}{ Tota } \\
\hline & & n & $(\%)$ & \\
\hline \multirow{2}{*}{ RQ saat ini } & $\mathrm{RQ} \leq 1$ & 8 & 40 & \multirow{2}{*}{20} \\
\hline & $\mathrm{RQ}>1$ & 12 & 60 & \\
\hline \multirow{2}{*}{ RQ 5 th } & $\mathrm{RQ} \leq 1$ & 7 & 35 & \multirow{2}{*}{20} \\
\hline & $\mathrm{RQ}>1$ & 13 & 65 & \\
\hline \multirow{2}{*}{ RQ 10 th } & $\mathrm{RQ} \leq 1$ & 6 & 30 & \multirow{2}{*}{20} \\
\hline & $\mathrm{RQ}>1$ & 14 & 70 & \\
\hline \multirow{2}{*}{ RQ 15 th } & $\mathrm{RQ} \leq 1$ & 6 & 30 & \multirow{2}{*}{20} \\
\hline & $\mathrm{RQ}>1$ & 14 & 70 & \\
\hline \multirow{2}{*}{ RQ 20 th } & $\mathrm{RQ} \leq 1$ & 5 & 25 & \multirow{2}{*}{20} \\
\hline & $\mathrm{RQ}>1$ & 15 & 75 & \\
\hline \multirow{2}{*}{ RQ 25 th } & $\mathrm{RQ} \leq 1$ & 5 & 25 & \multirow{2}{*}{20} \\
\hline & $\mathrm{RQ}>1$ & 15 & 75 & \\
\hline \multirow{2}{*}{ RQ 30 th } & $\mathrm{RQ} \leq 1$ & 4 & 20 & \multirow{2}{*}{20} \\
\hline & $\mathrm{RQ}>1$ & 16 & 80 & \\
\hline
\end{tabular}


Tabel 4. Persentase nilai Excess Cancer Risk $(E C R)$ saat ini, 5 th, 10 th, 15 th, 20 th, 25 th, dan 30 th Pekerja Pengrajin Sepatu di Kelurahan Tambak Oso Wilangun Surabaya 2016

\begin{tabular}{|c|c|c|c|c|}
\hline \multirow{2}{*}{ Pajanan } & \multirow{2}{*}{$E C R$} & \multicolumn{2}{|c|}{ Jumlah } & \multirow{2}{*}{ Total } \\
\hline & & n & $\%$ & \\
\hline \multirow{2}{*}{ ECR saat ini } & $\mathrm{ECR} \leq 10^{-5}$ & 0 & 0 & \multirow{2}{*}{20} \\
\hline & $\mathrm{ECR}>10^{-5}$ & 20 & 100 & \\
\hline \multirow{2}{*}{ ECR 5 th } & $\mathrm{ECR} \leq 10^{-5}$ & 0 & 0 & \multirow{2}{*}{20} \\
\hline & $\mathrm{ECR}>10^{-5}$ & 20 & 100 & \\
\hline \multirow{2}{*}{ ECR 10 th } & $\mathrm{ECR} \leq 10^{-5}$ & 0 & 0 & \multirow{2}{*}{20} \\
\hline & $\mathrm{ECR}>10^{-5}$ & 20 & 100 & \\
\hline \multirow{2}{*}{ ECR 15 th } & $\mathrm{ECR} \leq 10^{-5}$ & 0 & 0 & \multirow{2}{*}{20} \\
\hline & $\mathrm{ECR}>10^{-5}$ & 20 & 100 & \\
\hline \multirow{2}{*}{ ECR 20 th } & $\mathrm{ECR} \leq 10^{-5}$ & 0 & 0 & \multirow{2}{*}{20} \\
\hline & $\mathrm{ECR}>10^{-5}$ & 20 & 100 & \\
\hline \multirow{2}{*}{ ECR 25 th } & $\mathrm{ECR} \leq 10^{-5}$ & 0 & 0 & \multirow{2}{*}{20} \\
\hline & $\mathrm{ECR}>10^{-5}$ & 20 & 100 & \\
\hline \multirow{2}{*}{ ECR 30 th } & $\mathrm{ECR} \leq 10^{-5}$ & 0 & 0 & \multirow{2}{*}{20} \\
\hline & $\mathrm{ECR}>10^{-5}$ & 20 & 100 & \\
\hline
\end{tabular}

Setelah melakukan penilaian risiko dan mendapatkan hasil yang di luar dari nilai ambang batas maka hal selanjutnya yang dapat dilakukan adalah melakukan manajemen risiko. Hal ini dilakukan untuk meminimalisasi bahkan menghilangkan risiko bahaya yang ditimbulkan dari sumber bahaya di tepat kerja.

Pada manajemen risiko nonkarsinogenik yang digunakan adalah nilai RQ. Dalam menurunkan nilai konsentrasi risk agent maka nila $\mathrm{RQ}=1$ sehingga didapatkan nilai intake $=R f C$. Pada perhitungan ini data yang digunakan adalah rerata konsentrasi benzena (C) sebesar 1,35 mg/m3, laju inhalasi (R) sebesar $0.635 \mathrm{~m}^{3} / \mathrm{jam}$, waktu kerja (tE) selama 10,55 $\mathrm{jam} /$ hari, frekuensi pajanan $(f E)$ selama 346,75 hari/tahun, durasi pajanan (Dt) selama 30 tahun, berat badan $(\mathrm{Wb})$ pekerja adalah $65 \mathrm{Kg}$, dan tavg nonkanker adalah sebesar 30 tahun $\times 365$ hari/ tahun. Dalam penelitian ini dilakukan manajemen risiko berupa menghitung intake yang aman (I), menurunkan konsentrasi benzena $(\mathrm{C})$, mengurangi waktu kontak dengan sumber pajanan (tE), mengurangi frekuensi pajanan (fE) dan mengurangi durasi pajanan (Dt). Perhitungan untuk memperoleh nilai yang aman dilakukan pada responden 1 sebagai berikut:

$$
\begin{aligned}
& \mathrm{RQ}=1 \\
& \mathrm{I}_{\mathrm{nk}}=\mathrm{RfC} \\
& \mathrm{RQ}=\frac{\mathrm{I}_{\mathrm{nk}}}{\mathrm{RfC}} \\
& \mathrm{I}_{\mathrm{nk}}=\mathrm{RfC} \\
& \frac{\mathrm{C} \times \mathrm{R} \times \text { te } \times \mathrm{Fe} \times \mathrm{Dt}}{\mathrm{Wb} \times \text { Tavg }}=\mathrm{RfC}
\end{aligned}
$$

Sehingga untuk mencari nilai aman dapat

\begin{tabular}{|c|c|c|c|c|c|c|}
\hline \multirow{2}{*}{ No. Pekerja } & \multirow{2}{*}{ c awal $\left(\mathrm{mg} / \mathrm{m}^{3}\right)$} & \multirow{2}{*}{$\begin{array}{l}\text { c. } \text { aman } \\
\left(\mathrm{mg} / \mathrm{m}^{3}\right)\end{array}$} & \multirow{2}{*}{ t awal (jam/hari } & \multirow{2}{*}{$\begin{array}{c}\text { t aman } \\
\text { (jam/hari) }\end{array}$} & \multirow{2}{*}{$\begin{array}{l}\text { D awal } \\
\text { (tahun) }\end{array}$} & \multirow{2}{*}{ D aman (tahun) } \\
\hline & & & & & & \\
\hline 11 & 1.12 & 0.3 & 13 & 0.5 & 43 & 1.6 \\
\hline 12 & 1.12 & 2.1 & 12 & 3.5 & 8 & 2.4 \\
\hline 13 & 1.12 & 0.4 & 9 & 0.5 & 43 & 2.3 \\
\hline 14 & 1.27 & 0.4 & 15 & 0.7 & 23 & 1.1 \\
\hline 15 & 1.27 & 0.9 & 8 & 0.9 & 20 & 2.2 \\
\hline 16 & 1.27 & 0.6 & 10 & 0.8 & 27 & 2 \\
\hline 17 & 1.27 & 0.6 & 9 & 0.6 & 31 & 2.2 \\
\hline 18 & 2.91 & 0.9 & 10 & 0.5 & 25 & 1.2 \\
\hline 19 & 7.44 & 1.1 & 14 & 0.3 & 20 & 0.4 \\
\hline 20 & 7.44 & 2.3 & 8 & 0.4 & 14 & 0.7 \\
\hline
\end{tabular}
diturunkan dari rumus diatas menjadi sebagai berikut:

$$
\begin{aligned}
& \mathrm{C} \text { aman }=\frac{\mathrm{RfC} \times \mathrm{Wb} \times \text { tavg }}{\mathrm{R} \times \mathrm{tE} \times \mathrm{fE} \times \mathrm{Dt}} \\
& \mathrm{tE} \text { aman }=\frac{\mathrm{RfC} \times \mathrm{Wb} \times \mathrm{tavg}}{\mathrm{C} \times \mathrm{R} \times \mathrm{fE} \times \mathrm{Dt}}
\end{aligned}
$$

Tabel 5. Hasil Perhitungan Nilai Aman Pajanan Benzena Efek Kesehatan Non Karsinogenik pada Pekerja Pengrajin Benzena di Kelurahan Tambak Oso Wilangun Surabaya 2016 


$$
\text { Dt aman }=\frac{\mathrm{RfC} \times \mathrm{Wb} \times \operatorname{tavg}}{\mathrm{C} \times \mathrm{R} \times \mathrm{tE} \times \mathrm{fE}}
$$

Untuk hasil perhitungan selengkapnya hanya ditampilkan perhitungan pekerja yang berisiko terhadap non karsinogenik dapat dilihat pada tabel 5. Dari tabel perhitungan $\mathrm{C}$ aman, $\mathrm{t}$ aman, dan $\mathrm{Dt}$ aman di atas peneliti mengambil nilai aman risiko nonkanker dengan memilih nilai aman dari data hasil perhitungan paling mungkin diterapkan oleh pekerja pengrajin sepatu di Kelurahan Tambak Oso Wilangun Surabaya yaitu c aman sebesar $0,3 \mathrm{mg} /$ $\mathrm{m}^{3}$, $\mathrm{t}$ aman sebesar 7,2 jam/hari dan d aman sebesar 2,4 tahun.

Pada manajemen risiko karsinogenik yang digunakan adalah nilai ECR dengan menerapkan rumus sebagai berikut:

$$
\begin{aligned}
& \mathrm{ECR}=\mathrm{I}_{\mathrm{k}} \times \mathrm{CSF} \\
& \mathrm{RQ}=\frac{\mathrm{ECR}}{\mathrm{CSF}} \\
& \frac{\mathrm{C} \times \mathrm{R} \times \mathrm{tE} \times \mathrm{fE} \times \mathrm{Dt}}{\mathrm{Wb} \times \mathrm{Tavg}}=\frac{\mathrm{ECR}}{\mathrm{CSF}}
\end{aligned}
$$

Berdasarkan rumus perhitungan efek karsinogenik di atas, dapat diturunkan untuk mencari nilai aman $\mathrm{C}$, t, dan $\mathrm{D}$ aman sebagai berikut:

$$
\begin{aligned}
& \mathrm{C} \text { aman }=\frac{\mathrm{Wb} \times \mathrm{Tavg} \times \mathrm{ECR}}{\mathrm{R} \times \mathrm{tE} \times \mathrm{fE} \times \mathrm{Dt} \times \mathrm{CSF}} \\
& \mathrm{tE} \text { aman }=\frac{\mathrm{Wb} \times \mathrm{Tavg} \times \mathrm{ECR}}{\mathrm{C} \times \mathrm{R} \times \mathrm{fE} \times \mathrm{Dt} \times \mathrm{CSF}} \\
& \mathrm{Dt} \text { aman }=\frac{\mathrm{Wb} \times \mathrm{Tavg} \times \mathrm{ECR}}{\mathrm{C} \times \mathrm{R} \times \mathrm{tE} \times \mathrm{fE} \times \mathrm{CSF}}
\end{aligned}
$$

Untuk hasil perhitungan selengkapnya dapat dilihat pada tabel 6. Dari data di atas peneliti mengambil nilai aman dengan memilih nilai aman risiko kanker dari data hasil perhitungan paling mungkin diterapkan oleh pekerja pengrajin sepatu di Kelurahan Tambak Oso Wilangun Surabaya yaitu C aman sebesar $0,003 \mathrm{mg} / \mathrm{m}^{3}$, t aman sebesar 7,06 jam/ hari dan d aman sebesar 3,53 tahun.

\section{PEMBAHASAN}

Pengukuran konsentrasi benzena dilakukan di 8 titik sampling di lokasi kerja pengrajin sepatu di Kelurahan Tambak Oso Wilangun Surabaya menunjukkan konsentrasi tertinggi sebesar 2,333 ppm atau setara dengan $7,44 \mathrm{mg} / \mathrm{m}^{3}$ dan terendah sebesar $0,0129 \mathrm{ppm}$ atau setara dengan $0,04 \mathrm{mg} /$ $\mathrm{m}^{3}$. Konsentrasi benzena yang terukur di masingmasing titik berbeda, konsentrasi benzena yang terukur tinggi disebabkan karena beberapa hal diantaranya adalah produksi sepatu yang dihasilkan sangat banyak, sehingga lem yang digunakan juga mengikuti jumlah produksi sepatu yang dihasilkan.

Waktu pajanan menggambarkan jumlah jam kerja per hari di lingkungan kerja. Hasil penelitian didapatkan bahwa terendah pekerja bekerja terendah bekerja selama 6 jam per hari dan tertinggi bekerja selama 17 jam per hari. Hasil penelitian ini di atas nilai ambang batas dari jam kerja normal di mana sesuai dengan KEP.102/MEN/VI/2004 menjelaskan standarnya yaitu 7 jam kerja dalam sehari atau 6 hari dalam seminggu atau 8 jam kerja dalam sehari atau 5 hari dalam seminggu. Waktu kerja ini didapatkan hasil tertinggi $17 \mathrm{jam}$, sehari karena pesanan yang tinggi dan deadline produksi yang cepat sehingga pekerja berusahan keras untuk memenuhi target pesanan tersebut.

Frekuensi pajanan menunjukkan waktu yang dihabiskan pekerja untuk bekerja di industri pengrajin sepatu dalam rentang waktu 1 tahun. Hasil penelitian menerangkan bahwa pekerja menghabiskan waktu atau hari kerja terendah 260 hari/tahun dan tertinggi 365 hari/tahun.

Durasi pajanan menerangkan berapa lama pekerja bekerja di lokasi home industry sepatu. Durasi pajanan merupakan salah satu variabel yang digunakan untuk penilaian Intake (asupan) pajanan benzena ke dalam tubuh. Lama pekerja bekerja di home industry in bervariasi antara 3 sampai 43 tahun.

Hasil perhitungan tingkat risiko nonkanker tiap individu pada waktu saat ini, 5 tahun hingga 20 tahun didapatkan bahwa lebih dari $60 \%$ pekerja memiliki hasil perhitungan RQ $>1$. Sementara untuk pajanan selama 25 tahun hingga 30 tahun lebih dari $75 \%$ hingga $80 \%$ pekerja berisiko terhadap efek kesehatan nonkanker. Hasil tersebut menerangkan bahwa secara individu sebagian besar pekerja berisiko efek kesehatan nonkanker dan dalam kondisi yang tidak aman terhadap pajanan benzena.

Hasil perhitungan tingkat risiko kanker tiap individu pada waktu saat ini, tahun hingga 30 tahun seluruh pekerja sebanyak 20 orang $(100 \%)$ memiliki hasil perhitungan ECR $>10^{-5}$. Hasil tersebut menerangkan bahwa pada pajanan waktu saat ini 
Tabel 6. Hasil Perhitungan Nilai Aman Pajanan Benzena Efek Kesehatan Karsinogenik pada Pekerja Pengrajin Benzena di Kelurahan Tambak Oso Wilangun Surabaya 2016

\begin{tabular}{ccccccc}
\hline $\begin{array}{c}\text { No. } \\
\text { Pekerja }\end{array}$ & $\begin{array}{c}\text { c. awal } \\
\left(\mathbf{m g} / \mathbf{m}^{\mathbf{3}}\right)\end{array}$ & $\begin{array}{c}\mathbf{c} . \text { aman } \\
\left(\mathbf{m g} / \mathbf{m}^{\mathbf{3}}\right)\end{array}$ & $\begin{array}{c}\mathbf{t} \text { awal } \\
\text { (jam/hari) }\end{array}$ & $\begin{array}{c}\mathbf{t} \text { aman } \\
\text { (jam/hari) }\end{array}$ & $\begin{array}{c}\text { D awal } \\
\text { (tahun) }\end{array}$ & $\begin{array}{c}\text { D aman } \\
\text { (tahun) }\end{array}$ \\
\hline 1 & 0,04 & 0.004 & 9 & 0.93 & 34 & 3.53 \\
2 & 0,04 & 0.005 & 15 & 1.88 & 20 & 2.50 \\
3 & 0,04 & 0.004 & 17 & 1.79 & 16 & 1.69 \\
4 & 0.06 & 0.003 & 8 & 0.40 & 40 & 2.02 \\
5 & 0.06 & 0.002 & 14 & 0.58 & 36 & 1.49 \\
6 & 0.06 & 0.008 & 10 & 1.40 & 17 & 2.39 \\
7 & 0.06 & 0.006 & 8 & 0.74 & 30 & 2.77 \\
8 & 0.06 & 0.053 & 8 & 7.06 & 3 & 2.65 \\
9 & 0,15 & 0.007 & 8 & 0.36 & 25 & 1.12 \\
10 & 0,15 & 0.009 & 6 & 0.37 & 24 & 1.46 \\
11 & 1,12 & 0.002 & 13 & 0.02 & 43 & 0.08 \\
12 & 1,12 & 0.016 & 12 & 0.18 & 8 & 0.12 \\
13 & 1,12 & 0.003 & 9 & 0.02 & 43 & 0.12 \\
14 & 1,27 & 0.003 & 15 & 0.04 & 23 & 0.06 \\
15 & 1,27 & 0.007 & 8 & 0.04 & 20 & 0.11 \\
16 & 1,27 & 0.005 & 10 & 0.04 & 27 & 0.10 \\
17 & 1,27 & 0.004 & 9 & 0.03 & 31 & 0.11 \\
18 & 2,91 & 0.007 & 10 & 0.02 & 25 & 0.06 \\
19 & 7,44 & 0.008 & 14 & 0.02 & 20 & 0.02 \\
20 & 7,44 & 0.017 & 8 & 0.02 & 14 & 0.03 \\
\hline
\end{tabular}

hingga 30 tahun secara individu seluruh pekerja yang memiliki risiko kesehatan kanker dan dalam kondisi tidak aman terhadap pajanan benzena.

Konsentrasi pajanan benzena terhadap pekerja pengrajin sepatu di Kelurahan Tambak Oso Wilangun Surabaya dipengaruhi oleh kondisi udara di lokasi pekerja serta banyak tidaknya bahan berupa lem sepatu yang digunakan untuk proses produksi sepatu. Dari hasil perhitungan nilai pengendalian risiko kesehatan efek nonkanker dan efek kanker terhadap pajanan benzena yang aman pada pekerja pengrajin sepatu di Kelurahan Tambak Oso Wilangun Surabaya 2016 diperoleh nilai aman berikut konsentrasi aman (C) $0,003 \mathrm{mg} / \mathrm{m}^{3}$, waktu panajan aman (tE) 7,06 jam/hari, frekuensi pajanan (fE) 322 hari/tahun dan durasi pajanan (Dt) 3,53 tahun.

Pencegahan pajanan benzena membutuhkan peran aktif dari pekerja atau pemilik usaha untuk meminimalkan kontak pajanan benzena dengan pekerja. Salah satu cara yang dapat dilakukan adalah melengkapi pekerja dengan Alat pelindung Diri (APD). APD yang dapat digunakan adalah masker berbahan karbon aktif dan sarung tangan. Hal ini dilakukan karena pajanan benzena tidak hanya melalui inhalasi tetapi juga dapat melalui kulit.

Perhatian pemilik usaha juga harus diterapkan dengan memberikan makanan tambahan yang bergizi agar daya tahan tubuh pekerja dalam menetralisir racun dalam tubuh bekerja dengan maksimal.

Aspek perilaku berdasarkan pengamatan juga harus diperhatikan dalam melakukan manajemen risiko. Dapat dilakukan beberapa tindakan antara lain: Tempat penyimpanan kebiasaan meletakan bahan proses produksi sepatu seperti lem yang digunakan dengan sembarang tempat dapat memicu peluang terjadinya pajanan. Untuk itu perlu dibuatkan tempat khusus untuk menyimpan bahan produksi sepatu khususnya lem, salin penyimpanan penutupan wadah lem juga harus dilakukan dengan benar.

Ventilasi merupakan proses penyediaan udara luar yang segar yang dilakukan pertukaran dengan udara dalam ruangan secara alamiah. Fungsi utama ventilasi sebagai pertukaran udara luar dengan dalam ruangan, hal ini juga dimaksudkan untuk 
mengendalikan suhu udara supaya tidak panas dan pengap sehingga menambah asupan pajanan benzena. Menurut Peraturan Menteri Kesehatan R1 No. 1077/MENKES /PER/2011 tentang pedoman penyehatan udara dalam ruangan rumah ventilasi yang baik adalah dengan memenuhi kriteria luas ventilasi $>10 \%$ luas lantai tempat kerja.

Beberapa lokasi kerja memiliki luas ventilasi yang cukup besar danum beberapa lokasi kerja tidak tersedianya ventilasi yang cukup memadai untuk sirkulasi udara.

Kebiasaan merokok di tempat kerja menambah risiko pajanan benzena dalam asap rokok. Lokasi kerja yang dipenuhi bau dan uap benzena akan diperparah dengan kebisaan merokok pekerja di lokasi kerja. Hal ini perlu mendapat perhatian khusus dengan merokok di lokasi kerja serta timbulnya asap rokok membuat kondisi udara lingkungan kerja menjadi semakin minim oksigen dan memperparah asupan pajanan benzena. Kebiasaan merokok ini dapat dikurangi untuk menjaga kondisi tubuh agar dalam keadaan fit dan meminimalisasi keparahan akibat yang ditimbulkan dari efek pajanan benzena.

Personal hygiene adalah menjaga kebersihan pribadi menjadi tanggung jawab setiap indiviu atau pekerja. Pada saat sebelum, sesaat, dan sesudah melakukan pekerjaan membuat sepatu diharuskan setiap pekerja mencuci tangan dan melakukan pekerjaan tersebut dengan memakai sarung tangan. Ini dimaksudkan karena pajanan benzena selain melalui udara juga dapat melalui kulit yang dapat diabsorbsi oleh tubuh.

Alat pelindung diri dari hasil pengamatan pada saat penelitian sebagian besar pekerja mengambil, mengoleskan, meratakan lem menggunakan jari dengan tanpa memakai sarung tangan atau spatula sehingga menyisakan lem yang mengering di jari bahkan sampai menutupi telapak tangan.

Kebiasaan pekerja yang tidak memakai baju pada saat melakukan pekerjaan juga mendapatkan perhatian khusus. Untuk mengurangi risiko pajanan benzena melalui kulit. Pekerja tersebut melakukan hal demikian dikarenakan kondisi lingkungan yang panas dan pengap dan tubuh yang berkeringat. Pekerja lebih baik mengenakan pakaian agar terhindar dari risiko pajanan benzena.

\section{SIMPULAN}

Konsentrasi benzena paling rendah terdapat di lokasi kerja 1 sebesar $0,04 \mathrm{mg} / \mathrm{m}^{3}$ dan konsentrasi paling tinggi terdapat pada lokasi kerja 8 sebesar
$7,44 \mathrm{mg} / \mathrm{m}^{3}$. Konsentrasi benzena yang berbeda menyebabkan tingkat risiko pajanan yang berbeda pada setiap pekerja di lokasi kerja.

Perhitungan tingkat risiko (RQ) pada saat penelitian, sebagian besar pekerja terdapat nilai $\mathrm{RQ}>1$, artinya pada saat dilakukan penelitian terdapat pekerja dalam kondisi tidak aman akibat terpajan benzena.

Untuk perhitungan tingkat risiko kanker (ECR), sebagian besar pekerja terdapat nilai ECR $>10^{-5}$, artinya pada saat dilakukan penelitian terdapat pekerja dalam kondisi tidak aman untuk risiko kanker akibat pajanan benzena. Nilai batas aman bagi pekerja sebagai berikut konsentrasi aman (C) $0,003 \mathrm{mg} / \mathrm{m}^{3}$, waktu panjanan aman (tE) 7,06 jam/ hari, frekuensi pajanan (fE) 322 hari/tahun dan durasi pajanan (Dt) 3,53 tahun.

\section{DAFTAR PUSTAKA}

ATSDR. 2007. Tox Guide for Benzena. Diunduh dari http://www.atsdr.cdc.gov/toxguides/index.asp. sitasi 27 Maret 2016).

Chen,M., Chan,A. 1999. “China's "Market Economics in command" Footwear Workers Health in Jeopardy", International Journal of Health Services, Volume 29, Number 4, Pages 793-811, 1999. http://footwearsinfolinethree.tripod.com Sitasi 15 April 2016).

George D. Clayton \& Florence D. Clayton. 1994. Patty's Industrial Hygiene \& Toxicology. 4th edisi vol. 11 Part B. A Willey_Interscience Publication. John Willey \& Sons Inc. http://www.kemenperin. go.id/artikel/9745/Kemenperin Terus Dorong Pengembangan Industri Alas Kaki Nasional (sitasi 14 April 2016).

Kementrian Perindustrian. 2017. Kementrian Dorong Pengembangan Industri Alas Kaki Nasional. http://www.kemenperin. go.id/artikel/9745/Kemenperinterus DorongPengembanganIndustriAlasKakiNasional (Sitasi 17 januari 2017).

ILO. 2008. Menuju Tempat Kerja yang Lebih Produktif dan Aman: Petunjuk Praktis untuk Tempat kerja dengan Pekerja Usia 15-17 tahun, Kantor Perburuhan Internasional Jakarta; ILO, 2008.

ILO. 2004. Pekerja Anak Di Industri Sepatu Informal di Jawa Barat (Sebuah Kajian Cepat), Jakarta.

Krogholm, KS. 2010. Free Fruit at Workplace Invention Increases Total Fruit Intake: A Validation Study Using 24h Dietary Recall and 
Urinary Flavonoid Excretion. European Journal of Clinical Nutrition, 64: 1222-1228.

Lu, F. C. 2006. Toksikologi Dasar. Asas, Organ Sasaran, dan penilaian Risiko, Edisi Kedua. Penerbit Universitas Indonesia, hal 371-376.

Maryiantari, Ellyza S.2016. Thesis. Risk Assessment Pajanan Toluena Pada Pekerja Pengrajin Sepatu di Kelurahan tambak Oso Wilangun Surabaya Tahun 2016. Departmen Kesehatan Kerja, Fakultas Kesehatan Masyarakat, Surabaya.

National Occupational Health and Safety Commision. 1990, Industrial Organic Solvents Australian Government Publishing Service Canberra.

NRC. 1983. Risk Assessment in the federal government health. February 1992, volume 63, issue 6, pp 377-381 (sitasi 17 Januari 2017).

Permenaker.2004. Peraturan Menteri Tenaga Kerja dan Transmigrasi RI No. Kep 102/MEN/2004 tentang waktu kerja lembur dan upah kerja lembur.

Permenaker. 2011. Peraturan Menteri Tenaga Kerja dan Transmigrasi Republik Indonesia NOMOR PER.13/MEN/X/2011 tentang Nilai Ambang Batas Faktor Fisika dan Faktor Kimia di Tempat
Kerja. 2011. http://webcache.googleusercontent. com/search?q=cache:mf5eV-HihLEJ:www.djpp. kemenkumham.go.id/arsip/bn/2011/bn684-2011. $\mathrm{pdf}+\& \mathrm{~cd}=2 \& \mathrm{hl}=\mathrm{en} \& \mathrm{ct}=\mathrm{clnk} \& \mathrm{gl}=\mathrm{id}($ Sitasi 27 maret 2016).

SNI. 2005. Nilai Ambang Batas (NAB) Zat Kimia di Udara Tempat Kerja. 2005. Diunduh dari http://webcache.googleusercontent.com/ search?q=cache:DJzRvmd3u3 gJ:web.ipb. ac.id/ tml_atsp/test/SNI\%252019-0232-2005. $\mathrm{pdf}+\& \mathrm{~cd}=1 \& \mathrm{hl}=\mathrm{en} \& \mathrm{ct}=\mathrm{clnk} \& \mathrm{gl}=\mathrm{id} . \quad($ Sitasi 27 maret 2016).

Sugiharto, Eram T. P. 2009. Hubungan antara Perilaku Penggunaan Insektisida Dalam Pengendalian Hama Ulat Bawang (Spodoptera Exigua Hbn) dengan Tingkat Keracunan Petani Penyemprot Bawang Merah di Desa Bangsal Rejo, Kec. Wedari Jaksa, Kab. Pati. Jurnal Kemas, 4 (2): 132-139.

Susilowati, B. 2011. Skripsi. Risiko Kesehatan Terhadap Panajan Benzena Pada Pekerja Industri Sepatu Kulit di PIK Pulogadung Tahun 2011. Departemen Kesehatan Lingkungan Fakultas Kesehatan Masyarakat. Depok. 